\title{
Empirical Research on the Mechanism of Logistics Collaborative Work of China's Coastal Ports with Plural Subjects
}

\author{
Youming Zhu \\ ZheJiang Business College 470 BinWen Road Binjiang district Hangzhou, China \\ zym0573@163.com
}

Keywords: Zhejiang; Port logistics; Coordination mechanism

\begin{abstract}
As an important part of the marine economy and an important guarantee for the development of the coastal areas, the development of China's coastal port logistics is insufficient and the port logistics and the local economic development are not in harmony. Based on the perspective of synergetic theory, this paper analyzed the multiple subjects and multi-layer structure of port logistics, based on the cooperative mechanism of port logistics, process mechanism and external mechanism, built the model of port logistics coordination degree, carried out quantitative analysis on the coordination degree of the coastal port logistics in Zhejiang province and further studied the port logistics coordination mechanism. Based on the coordination degree of Zhejiang coastal port logistics and the present situation of Zhejiang coastal port logistics, this paper put forward the policy recommendations.
\end{abstract}

\section{Introduction}

Chinese market economy starts first from the coastal area. In order to encourage foreign economic cooperation and technological exchanges, in 1984,fourteen port cities such as Qinhuangdao, Tianjin, Dalian were set as coastal open cities. Then the Yangtze River Delta, Pearl River Delta and Fujian Zhangzhou Quanzhou Delta as well as Liaodong Peninsula and Jiaodong peninsula were set as the coastal economic zones. Stimulated by the dividend policy of opening up to the outside world, the GDP of China's coastal port cities have always been at the forefront of the Inland cities and they played an important role in the international trade activities. There is no doubt that encouraging and promoting the development of coastal port construction and port logistics will be a new incentive to China's economic development. But in the economic development of coastal port cities, there are still some non-coordinated development between port logistics and economic development in a certain extent and the development of the coastal port logistics has a relatively low contribution to the overall economic development of the region. Because the port logistics is a systematic project involving many factors and many levels, with a number of subsystems, based on the perspective of different subjects, it is of special value to further study the cooperation mechanism of port logistics. This paper with the help of the Synergetic theory, analyzed the multi- subject cooperative work mechanism of China's coastal port logistics and taking Zhejiang coastal port logistics as an example to analyze the abstract. Do not use abbreviations in the title or heads unless they are unavoidable.

\section{Literature Review}

Synergetic theory was established by German scholar Hermann Haken in 1970s and aims to study the evolution law of how complex system composed of several subsystems operates from disorder to order through cooperation. In recent years, scholars at home and abroad applied the Coordinative Theory in the logistics efficiency and effectiveness of the upgrade and achieved a lot of useful results. Coronad and Acosta, taking Algeciras port of Spain as an example, studied the interactive relationship between port container logistics and regional economy [1]. Yang Chengxin and Jung combined the theory with the port logistics system, studied port logistics coordination mechanism from qualitative state coordination, quantity state collaboration, space coordination and time coordination [2]. Based on 
the analysis on the present situation and the necessity of the development of the coastal port logistics in Fujian, He na and Li Na put forward the policy suggestions on the coordinated development of Fujian coastal port logistics [3]. Cao Yi and Zhao Shulei's studies believe that the port logistics promotes economic growth, urban economic development plays a fundamental role in the development and promotion of port logistics and put forward the strategy of the coordinated development of Tangshan economy and Caofeidian port logistics [4]. Zhang Yun proposed the concept of the collaborative development of port logistics of Jinji [5] [6] [7]. Through consulting the literature, the author found that the research on the combination of the coordination theory and the port logistics is still of shortage, while most of the existing researches focus on qualitative research [8][9]. And from the point of view of the research object, the coastal port logistics research of a specific region is lack. The development of the port logistics can not get rid of the economic development in the region, Elements exchanges will be inevitably involved into the connections between port and port and connections among ports, logistics enterprises, manufacturing enterprises, commercial enterprises and local government and multi governance and collaborative development is bound to be the ultimate pipeline to enhance the port logistics efficiency and effectiveness. Therefore, it is the only way to ensure the coordinated development of port logistics and regional economy to explore the mechanism of multi subjects cooperative work mechanism and the operation mode of port logistics [10].

\section{Construction of Cooperative Work Mechanism of Port Logistics of Multiple Subjects}

The port logistics system is a system composed of a number of subjects, with multiple levels and multiple factors. It is a open and complex system with random phenomenon and in accordance with the characteristics of the research object. Therefore, it is feasible to combine the theory with the port logistics to study.

Port Logistics System Structure and Coordinated Association. Port logistics coordination refers to the port logistics system under the control and guidance of the order parameter in a certain period of time achieves a balanced state --that is to reach a coordinated state. The port logistics system is a system composed of multiple subjects, multiple levels and multiple factors. The port logistics system is composed of several main subjects, which is affected jointly by many factors in the internal environment and the external environment of the system. Therefore, the port logistics coordination is a multi subject cooperative state under the common function of various factors in the internal and external environment of the port logistics system. According to the composition of multiple subjects of port logistics, the port logistics system can be divided into support level, operation level, management level, decision-making level and system level, as is shown in Figure 1.Port logistics infrastructure, the port industry and hinterland economy provide the support for the port logistics system, and form the supporting level of port logistics system. The operation level is mainly composed of the specific activities directly related to the port logistics, such as goods consolidation, inventory, distribution, transfer, load and unload, processing and trade. Port logistics system management includes port logistics operation, port logistics information and port logistics services, etc. Port logistics policy, port logistics planning and sustainable development of port logistics constitute the decision-making level of the port logistics. Multi subject in the port logistics system ultimately affects the regional economic system, social system and environmental system through the integration of various elements, and constitute the system level of the port logistics. High level coordination provides protection for the low level coordination and low level coordination is the basis of high level coordination in the coordination interior.

Analysis on the Port Logistics Coordination Mechanism. Through the analysis of the structure of the multi subject, multi factors and multi level of the port logistics and the literature review, this paper analyzed the port logistics coordination mechanism from port logistics coordination multiple subject interests mechanism, coordination process mechanism and coordination external mechanism.

First, the mechanism of multi subject coordination of port logistics. The goal of port logistics coordination is to achieve the organic combination of each subsystem in the port logistics system by 
integrating and optimizing the allocation of various factors. The overall benefit of the port logistics system is not the simple addition of multiple subjects, but the effect of "1-I-1>2"--that is to maximize the overall efficiency of the port logistics system through the port logistics coordination mechanism. To maximize the benefits is also to realize the synergy mechanism in the Multi subject port logistics system.

Secondly, Mechanism of multi subject cooperative process of port logistics. In the port logistics multi subject coordination process, competition cooperation mechanism, coupling mechanism, resources integration mechanism, learning mechanism and innovation mechanism are formed. The effect of multiple subjects in the process of coordination can be referred to as the mechanism of cooperative process. In the port logistics system, there is a competition between the ports and the focus of competition exists in the source and the resources of the common hinterland. At the same time, the competition of the port in the information, talent, capital and other aspects is becoming increasingly fierce. Excessive competition between ports can lead to unnecessary waste of resources, while under the premise of maintaining a competitive relationship, cooperation between multiple subjects and coordination in the competition are conducive to the development of the common hinterland and the rational use of resources and the formation of competitive cooperation mechanism. The port logistics system with a single port as the center is a subsystem of the port and the goods supply side, the demand side of the goods, the government departments, banks and financial institutions and the port logistics services. In fact, port logistics involves many aspects of transportation, loading and unloading, warehousing, processing, circulation and information services, and these services are provided by different departments or agencies. Building coupling mechanisms among agencies to coordinate the parties taking the port logistics as centers and form the coupling effect. The port logistics system has many kinds of resources, but in the port logistics system, the distribution of the resources and the demand of the development of the port logistics are usually not appropriate and resource integration is the process of optimizing the allocation of resources. Based on the analysis of the function orientation of the port logistics multi subject, to optimize the allocation of resources and achieve resource sharing is the guarantee to improve the efficiency of resource use and achieve the scale benefit of the port logistics and the final integration mechanism of port logistics resources. The coordination between the multiple subjects of port logistics will inevitably require the port to learn from each other in the process of dealing with the problem. Learning process is also the process of port logistics to adapt to internal and external environment changes, including business process learning, organizational learning and management system learning and other aspects of the content. The learning process of inside port and between ports will improve the performance of the port logistics to a certain extent, and form the port logistics learning mechanism. The cooperation between multiple subjects of port logistics provides a comparable target for the port's own understanding, and it also plays a role in promoting the innovation of port logistics indirectly. However, it is easier for multi subject with unified coordination to form the innovation mechanism of Port Logistics through the agglomeration of innovative resources.

Third. Multi subject coordination external mechanism of Port Logistics. The multi subject cooperative mechanism of port logistics is one of the components of the port logistics system, which runs through the process of the coordination of the port logistics. The synergy mechanism of external mechanism and dynamic mechanism and the process mechanism of synergy jointly affect the port logistics system, which constitute the coordination mechanism of the port logistics. The port logistics coordination external mechanism can be discussed from two aspects, namely dynamic coordination and macro-control. Port logistics system is a dynamic system. In coordinated state, logistics system achieves a balance, but the internal elements are still with dynamic changes. In fact, the cooperation of the port logistics system is the dynamic state. In fact, the coordination of the port logistics system is in the dynamic state. There is a conflict of interest in the process of coordination of multiple subjects, and it will be with low efficiency and even difficult to solve the situation only through coordination between the relevant subjects, and it needs Macro control of the port logistics. Port Association organizations and government departments can become the port logistics macro regulation and control organization to make the relevant subject solve the problem through a variety of administrative means. 


\section{Empirical Analysis}

Port Logistics Coordination Model. Suppose that the order parameter vector of the subsystem of the port logistics system is $\mathrm{Q}_{\mathrm{d}}=\left(\mathrm{Q}_{1 \mathrm{~d}}, \mathrm{Q}_{2 \mathrm{~d}}, \mathrm{Q}_{3 \mathrm{~d}}, \cdots \mathrm{Q}_{\mathrm{nd}}\right), \mathrm{n} \geq 1$.In synergetic theory, the degree of order of the system can be divided into two types, namely, growth type and recession type system degree of order.

Definition $1, \mathrm{Q}_{\mathrm{d}}$ is the order parameter variable for port logistics subsystem and order parameter component of port logistics subsystem is $\mathrm{Q}_{\mathrm{id}}$, that is System degree of order of order parameter component $\mathrm{Q}_{\mathrm{id}}$ is $\mathrm{U}\left(\mathrm{Q}_{\mathrm{id}}\right)$, as is shown in the formula (1):

$$
U\left(Q_{i d}\right)=\left\{\begin{array}{l}
\frac{\mathrm{Q}_{\mathrm{id}}-\mathrm{B}_{\mathrm{id}}}{\mathrm{A}_{\mathrm{id}}-\mathrm{B}_{\mathrm{id}}} \mathrm{Q}_{\mathrm{d}} \text { were order degree of growth } \\
\frac{\mathrm{A}_{\mathrm{id}}-\mathrm{Q}_{\mathrm{id}}}{\mathrm{A}_{\mathrm{id}}-\mathrm{B}_{\mathrm{id}}} \mathrm{Q}_{\mathrm{d}} \text { were Order degree of attenuation }
\end{array}\right.
$$

In formula (1), $A_{i d}$ and $B_{i d}$ constitute the interval of taking value of $Q_{i d}$, that is $Q_{i d} \in\left[B_{i d}, A_{i d}\right]$ it can be done to change $A_{i d}$ and $B_{\text {id }}$ to reduce or enlarge $U\left(Q_{i d}\right), U\left(Q_{i d}\right)$ indicates the contribution of the component to the system degree of order. Definition $2 \mathrm{U}\left(\mathrm{Q}_{\mathrm{id}}\right)$ can be turned into $\mathrm{V}\left(\mathrm{Q}_{\mathrm{d}}\right)$, total contribution value of system order degree" measuring the order parameter variable $\mathrm{Q}_{\mathrm{d}}$ by specific integration rules, that is system order degree of order parameter variable $\mathrm{Q}_{\mathrm{d}}$. Among them, the integration rules can be realized by the linear weighted sum method, as is shown in the formula (2):

$$
V\left(Q_{d}\right)=\sum_{i=1}^{n} \omega_{i} U\left(Q_{i d}\right), \omega_{i}>0, \sum \omega_{i}=1
$$

By definition 2, $\mathrm{V}\left(\mathrm{Q}_{\mathrm{d}}\right)$ belongs to[0,1], the higher the $\mathrm{V}\left(\mathrm{Q}_{\mathrm{d}}\right)$ is, the greater the Total contribution degree of order parameter variable $\mathrm{Q}_{\mathrm{d}}$ to System orderly state is , that is Order degree of the system is

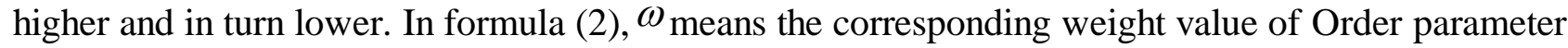
component $\mathrm{Q}_{\text {id }}$.

Definition 3, Assuming that the system is $t$ at an initial time of operating, order parameter order degree of the subsystem of the system is $\mathrm{V}_{1}\left(\mathrm{Q}_{\mathrm{j}}\right), \mathrm{j}=1,2,3 \cdot \mathrm{m}$, the coordination degree of port logistics system is defined as SPLS.

$$
\mathrm{SPLS}=\operatorname{sig} *\left(\sqrt[m]{\left.\prod_{i=1}^{m}\left|V_{1}\left(Q_{j}\right)-V_{0}\left(Q_{j}\right)\right|\right)} \quad \operatorname{sig}=\left\{\begin{array}{l}
1, V_{1}\left(Q_{j}\right)>V_{0}\left(Q_{j}\right), j=1,2,3, \cdots, m \\
-1, V_{1}\left(Q_{j}\right) \leq V_{0}\left(Q_{j}\right), j=1,2,3 \cdots, m
\end{array}\right.\right.
$$

The coordination degree of port logistics system can be obtained by the geometric average method. The higher the value is, the higher the degree of coordination, and in turn the lower the degree of the system. The purpose of Sig judgment function is to ensure that when V1 (Qj) > V0 (Qj) is true, the system has positive synergy.

Zhejiang Coastal Port Logistics Coordination Degree. The construction of the integrated index system of the port logistics system is the basis of the research on the coordination degree of Zhejiang coastal port logistics. On the basis of literature research, combined with the characteristics of port logistics, it follows the principles of scientific, systematic, accurate, dynamic and feasibility, and constructs a comprehensive index system of port logistics system, as is shown in Table 1

Table 1 Evaluation index system of port logistics system

\begin{tabular}{|c|c|}
\hline First indexes & Secondary indexes \\
\hline \multirow{3}{*}{ Port logistics infrastructure } & Berthnumber X1 for production wharf \\
\cline { 2 - 2 } & Million tons of production with wharf berth X2 \\
\cline { 2 - 2 } & Frontage Length X3 \\
\cline { 2 - 2 } & Highway traffic mileage X4 \\
\hline Port logistics scale & Cargo handling capacity X5 \\
\hline
\end{tabular}


Table 1, cont.

\begin{tabular}{|c|c|}
\hline \multirow{2}{*}{ Hinterland economic conditions } & Container handling capacity X6 \\
\cline { 2 - 2 } & Foreign trade cargo capacityX7 \\
\cline { 2 - 2 } Port area- industry conditions & Port city GDP X8 \\
\cline { 2 - 2 } & Tetail sales of social consumer goods X9 \\
\cline { 2 - 2 } & Proportion industry structure X11 \\
\cline { 2 - 2 } Port logistics support & Fixed assets investment X12 \\
\hline \multirow{3}{*}{ Above scale industrial output value X13 } \\
\cline { 2 - 2 } & Port logistics informatization degree X14 \\
\cline { 2 - 2 } & Port city financial development degree X15 \\
\cline { 2 - 2 } & Port logistics innovation capability X16 \\
\hline
\end{tabular}

In this paper, Aid Max(Qid),Bid=Max(Qid) The system order degree can be transformed into data standardization process. Refer to statistical data from 2007 to 2015 in Zhejiang coastal areas. The weights of each index gained by Diquan method are shown in Table 2

Table 2 The weight of each index

\begin{tabular}{ccccccccc}
\hline Index & X1 & X2 & X3 & X4 & X5 & X6 & X7 & X8 \\
\hline Weight & 0.027 & 0.034 & 0.028 & 0.016 & 0.035 & 0.102 & 0.057 & 0.030 \\
Index & X9 & X10 & X11 & X12 & X13 & X14 & X15 & X16 \\
Weight & 0.120 & 0.054 & 0.013 & 0.124 & 0.128 & 0.058 & 0.056 & 0.058 \\
\hline
\end{tabular}

By definition 1, we can get the system order degree of each order parameter component of port logistics in Ningbo, Jiaxing, Wenzhou and Zhejiang. We can get weight and system order degree of each order parameter component by Table 2 .we can get system order degree of each order parameter variable according to the formula (2). And based on this ,through the formula (3), we can obtain the port logistics coordination degree as is shown in Table 3. Through the calculation of the average value of the coordination degree of the port city port logistics, Zhejiang coastal port logistics coordination degree can be obtained, as is shown in Table 3.It can be known that the coordination degree of the coastal port logistics in the early stage of Zhejiang is negative, that is, the Zhejiang coastal port logistics from 2007 to 2011 was non- cooperative or not in a coordinated state. But after that there is a rise in the trend and negative values appeared in 2014.

Table 3 The coordination degree of the three cities along the coast of Zhejiang Province

\begin{tabular}{cccccccccc}
\hline & 2007 & 2008 & 2009 & 2010 & 2011 & 2012 & 2013 & 2014 & 2015 \\
\hline Ningbo & 0.014 & -0.016 & -0.014 & 0.016 & -0.017 & 0.020 & 0.015 & -0.017 & 0.016 \\
Jiaxing & -0.008 & 0.0107 & -0.011 & 0.026 & 0.025 & 0.026 & 0.014 & 0.030 & -0.012 \\
Wenzhou & -0.010 & -0.0012 & 0.012 & -0.015 & -0.020 & 0.032 & 0.021 & -0.017 & 0.020 \\
Zhejiang & -0.001 & -0.006 & -0.004 & 0.009 & -0.004 & 0.026 & 0.017 & -0.001 & 0.008 \\
\hline
\end{tabular}

\section{Policy Recommendations}

Based on the coordination degree of Zhejiang coastal port logistics and the present situation of Port Logistics in the process of research, this paper puts forward the policy recommendations as follows:

Reconstruct the Port Logistics Development System. First, in strategy, strategic partnership should be established between coastal port and port and port and local city to achieve consensus on the development goals and to reach a consensus on the way to work together. Second, change organizational affiliation. Local government departments can change the management mechanism with 
multi ports independent on or subjection to the local city into port group, to achieve cross administrative with the heads of local government departments to eliminate administrative costs and improve logistics efficiency. Third, implement unified planning for different ports, dislocation development and highlight the effectiveness of the group.

Improve the Normalization of the Port Logistics. The improvement of efficiency of port logistics should not only rely on the investment in infrastructures such as docks, stations and shore bridge, but also the improvement of the Port information construction and technical level as well as the reasonable readjustment of proportion of production factors such as the capital and technology so as to realize the improvement of the port logistics efficiency. Therefore, strengthen the port logistics infrastructure and at the same time, improve the level of port logistics information to makes the storage, transportation and other aspects of the line achieve the best and maximum efficiency under the optimal allocation of information system.

Optimize the Industrial Structure of Port Area. The relationship between the evolution of industrial structure and economic development of coastal ports is with mutual support and mutual promotion. Zhejiang coastal port city's industry is mainly concentrated in the second industry, and the development of the coastal third industrial structure is still slow. It is the only way to realize the coastal state strategy of Zhejiang to accelerate the transformation of the port's industrial structure to provide support for the development of Zhejiang coastal port logistics.

Actively Build Multi-Subject Coordinated Development Platform. First, actively promote the co-transport by river-sea. Through the seamless connection between the port and inland waterway transport, reduce transport links, transshipment times and operating procedures; shorten the cycle of transportation to adapt to the owners' service requirements of velocity and logistics. Second, actively implement the sea- rail transport. According to the characteristics of the location of the port, implement the sea- rail transport selectively, realize the intensive management of logistics, reduce costs, and quickly respond to the market.

\section{References}

[1] A. E .Coronado C.S.Mondragon., et al. Intelligent transport systems in multimodal logistics: A case of role and contribution through wireless vehicular networks in a seaport location. International fournal of Production Economics, 137(2012)165-175.

[2] X.Yang,H,Rong. On the coordination mechanism of port logistics system. Journal of Comprehensive transportation, 11 (2008):56-60.

[3] N He, N Li. Research on the strategy of coordinated development of port logistics in South Fujian. Journal of Harbin University of Commerce (Social Science Edition) ,48(2012) 67-71.

[4] Y.Cao, Shulei. Zhao Study on the improvement of the effect of urban economic development on the quality of port logistics, modern commerce and trade, 33(2014) 101-106.

[5] Y.Zhang.Tianjin and Hebei Port Logistics collaborative development concept, logistics and procurement, 30(2010) 62-64.

[6] W.Ba.Port logistics planning based on multimodal transport, Logistics Sci-Tech, 8(2016)17-22.

[7] H.Ma.Y.Xi. Research on the structure and characteristics of logistics capability in supply chain environment. , Chinese Journal of Management,9(2011)34-38.

[8] Y.Huang. The relationship between port logistics industry cluster and port economic development. Journal of Manager,11(2009):77-81.

[9] S.Jin, Chenqiu, Xia. Research on the construction of the integrated information platform for the electronic commerce of the port logistics park. Journal of China Water Transport,8(2015)53-54.

[10] H.Long. Research on the influence of port logistics capability on economic growth, Journal of NingboUniversity, 5(2014)55-58. 